\title{
Mutational Analysis in Pediatric Thyroid Cancer and Correlations with Age, Ethnicity, and Clinical Presentation
}

\author{
Maria Eleni Nikita, ${ }^{1}$ Wen Jiang, ${ }^{2}$ Shih-Min Cheng, ${ }^{3}$ Feras M. Hantash, ${ }^{3}$ Michael J. McPhaul, ${ }^{3}$ \\ Robert O. Newbury, ${ }^{4}$ Susan A. Phillips, ${ }^{1}$ Richard E. Reitz, ${ }^{3}$ Frederic M. Waldman, ${ }^{3}$ and Ron S. Newfield ${ }^{1}$
}

Background: Well-differentiated thyroid cancer (WDTC) incidence in pediatrics is rising, most being papillary thyroid carcinoma (PTC). The objective of the study was to assess the prevalence of different mutations in pediatric WDTC and correlate the genotype with the clinical phenotype.

Methods: This is a single-center retrospective study. Thyroid tissue blocks from 42 consecutive pediatric WDTC patients who underwent thyroidectomy between 2001 and 2013 were analyzed at Quest Diagnostics for BRAFV600E, RAS mutations $(N, K, H)$, and RET/PTC and PAX8/PPAR $\gamma$ rearrangements, using validated molecular methods. Thyroid carcinomas included PTC, follicular thyroid carcinoma (FTC), and follicular variant of PTC (FVPTC). Results: Thirty-nine samples (29 females) were genotyped. The mean age at diagnosis was 14.7 years (range 7.918.4 years), and most were Hispanic $(56.4 \%)$ or Caucasian $(35.9 \%)$. The mean follow-up period was 2.9 years. Mutations were noted in 21/39 $(53.8 \%)$, with both $B R A F^{V 600 E}(n=9)$, and RET/PTC $(n=6)$ detected only in PTC. Mutations were detected in 2/5 FTC (PAX8/PPAR $\gamma$ and NRAS) and 3/6 FVPTC cases (PAX8/PPAR $\gamma)$. Of 28 PTC patients, $57.1 \%$ had mutations: $32.1 \%$ with $B R A F^{V 600 E}, 21.4 \%$ with $R E T / P T C$, and $3.6 \%$ with $N R A S$. Of patients with $B R A F^{V 600 E}, 77.8 \%$ were Hispanic and $88.9 \%$ were $>15$ years, while all $R E T / P T C$-positive patients were $\leq 15$ years $(p=0.003)$. Tumor size, lymph node involvement, and distant metastasis at diagnosis (or soon after ${ }^{131} \mathrm{I}$ ablation) did not vary significantly based on the mutation.

Conclusions: $B R A F^{V 6 O O E}$ was the most common mutation, especially in older and Hispanic adolescents. A larger, ethnically diverse pediatric cohort followed long term will enable the genotypic variability, clinical presentation, and response to therapy to be better assessed.

\section{Introduction}

$\mathbf{T}$ HYROID CANCER REPRESENTS THE THIRD most common pediatric solid tumor and the most common endocrine malignancy (1). The incidence of thyroid cancer in the United States has been rising in both adults and pediatric patients. Based on the Surveillance, Epidemiology, and End Results (SEER) database, the average age-adjusted annual incidence for thyroid cancer in children 0-20 years old, from 2008 to 2011, was 0.886 per 100,000 persons (2). Pediatric thyroid carcinoma and especially papillary thyroid carcinoma (PTC) has a more favorable course compared with adults, with a disease-specific mortality of $<2 \%$ (3). However, at the time of diagnosis, pediatric patients often present with more advanced disease, and they frequently suffer from persistent or recurrent disease due to metastatic lymph nodes or lung metastases (3).
The prevalence of different mutations in adult thyroid cancer has been presented in various reports. The most common genetic alteration is $B R A F(29-83 \%)$ with an overall prevalence of $\sim 44 \%$ (4-6). The prevalence of RET/PTC rearrangements in adults has been estimated to be $\sim 35 \%$ (7). Point mutations in $H R A S, K R A S$, and NRAS are less frequent in PTC, with an overall frequency of 10-20\% (8), whereas a higher prevalence $(40-50 \%)$ has been reported in follicular carcinomas $(9,10)$. Finally, PAX8/PPAR $\gamma$ rearrangements are found in $30-40 \%$ of follicular adult thyroid carcinoma, and rarely in FVPTC (11).

The prevalence and type of mutations appear to differ between adult and childhood thyroid carcinoma, though pediatric data are still limited (1). Initial reports with relatively small sample sizes have shown a much lower prevalence of $B R A F$ mutations in pediatric populations, ranging from $0 \%$ to $24 \%$ (12-14). In contrast, two recent reports demonstrated a

\footnotetext{
${ }^{1}$ Division of Pediatric Endocrinology; ${ }^{2}$ Division of Pediatric Otolaryngology; ${ }^{4}$ Department of Pathology; University of California, San Diego, and Rady Children's Hospital San Diego, California.

${ }^{3}$ Hematology and Oncology, Quest Diagnostics Nichols Institute, San Juan Capistrano, California.

(C) Nikita et al. 2016; Published by Mary Ann Liebert, Inc. This Open Access article is distributed under the terms of the Creative Commons Attribution Noncommercial License (http:///creativecommons.org/licenses/by-nc/4.0/) which permits any noncommercial use, distribution, and reproduction in any medium, provided the original author(s) and the source are credited.
} 
much higher prevalence of the mutation in pediatric PTC of $34.5 \%$ and $71.4 \%(15,16)$. Sporadic pediatric thyroid cancer shows a variable prevalence of RET/PTC rearrangements, ranging from $37.5 \%$ to $71 \%$, with $R E T / P T C 1$ being the predominant mutation (17-19). RAS mutations are uncommon in children and adolescents (20-22). The significance of these genetic mutations in terms of tumor presentation, progression, and response to therapeutic interventions in pediatrics is not clear. Therefore, this study investigated the rate of the common mutations implicated in non-medullary pediatric welldifferentiated thyroid carcinoma (WDTC) in patients who underwent surgery at the authors' institution. This is the first pediatric study where all four mutation classes were examined on thyroidectomy-obtained thyroid tissue, and the findings were recently reported as an abstract (23). Correlations between genotype and clinical phenotype were also explored.

\section{Materials and Methods}

Patients aged $\leq 18$ years old who underwent thyroid surgery and who were treated at Rady Children's Hospital San Diego (RCHSD) for thyroid cancer were included after Institutional Review Board (IRB) approval was obtained. The patients were identified based on ICD9 codes (193, 244.0, 244.1), and review of pathology records. Patients with medullary carcinoma were excluded. Forty-six consecutive children and adolescent patients with WDTC were identified between 2001 and 2013. Tumors of patients with only one tissue block available were not submitted for analysis. A total of 42 formalin-fixed, paraffin-embedded (FFPE) tissue blocks from the thyroid gland obtained at the time of thyroid surgery were sent to Quest Diagnostics Nichols Institute for mutational analysis as a collaborative research study. The protocol was IRB approved to analyze these blocks for commercially available $B R A F, N R A S, H R A S$, and KRAS point mutations, as well as $R E T / P T C$ and $P A X 8 / P P A R \gamma$ rearrangements, using validated molecular methods.

Total nucleic acid (DNA and RNA) was extracted from thyroid FFPE specimens using an Agencourt FormaPure FFPE extraction Kit (Beckman Coulter, Indianapolis, IN) according to the manufacturer's protocol (24). Molecular testing was performed blinded to the result of cytopathological diagnosis. $B R A F^{V 600 E}$ and $B R A F^{K 601 E}$ mutations were detected by real-time polymerase chain reaction (PCR) using allele-specific primers and probes using TaqMan Universal PCR Mix (Life Technologies, Grand Island, NY). The mixture was pre-amplified for 14 cycles on ABI Veriti with denaturation at $95^{\circ} \mathrm{C}$ for $15 \mathrm{sec}$, annealing at $56^{\circ} \mathrm{C}$ for $30 \mathrm{sec}$, and extension at $72^{\circ} \mathrm{C}$ for $30 \mathrm{sec}$. The PCR products were then cleaned up with Ampure (Beckman Coulter) and subjected to 40 cycles of PCR amplification on ABI 7900 (Life Technologies) with denaturation at $95^{\circ} \mathrm{C}$ for $15 \mathrm{sec}$, annealing at $62^{\circ} \mathrm{C}$ for $30 \mathrm{sec}$, and extension at $68^{\circ} \mathrm{C}$ for $30 \mathrm{sec}$, and the result was analyzed by SDS software (Life Technologies). Sanger sequencing was performed on the positive cases for $B R A F^{V 600 E}$. Six out of 10 samples verified the presence of $B R A F^{V 600 E}$ mutation, while four of the samples failed to amplify, likely not having enough DNA and/or having fragmented DNA smaller than the target size for Sanger sequencing.

$R A S$ mutations were detected by pyrosequencing targeting codons 12, 13, and 61 of $H R A S, K R A S$, and NRAS. Extracted DNA was mixed with biotinylated primers and subjected to 45 cycles of PCR amplification (denaturation at $94^{\circ} \mathrm{C}$ for $30 \mathrm{sec}$, annealing at $60^{\circ} \mathrm{C}$ for $30 \mathrm{sec}$, and extension at $72^{\circ} \mathrm{C}$ for $30 \mathrm{sec}$ ). After PCR, DNA strands were separated on a PyroMark Q96 vacuum workstation (Qiagen, Valencia, CA). Then pyrosequencing was performed using a PyroMark Q96 MD instrument (Qiagen) according to the manufacturer's protocol.

RET/PTC1, RET/PTC3, and PAX8/PPAR $\gamma$ rearrangements were detected by real-time reverse transcription PCR. Extracted RNA was first reverse transcribed into cDNA using Superscript III (Life Technologies), then mixed with sequence-specific primers and probes in TaqMan Universal PCR Mix. The mixture was subjected to 45 cycles of PCR amplification $\left(95^{\circ} \mathrm{C}\right.$ for $15 \mathrm{sec}$, then at $60^{\circ} \mathrm{C}$ for $\left.60 \mathrm{sec}\right)$ on ABI 7900, and the result was analyzed by SDS software. For $P A X 8 / P P A R \gamma$, the cDNA was pre-amplified as described above before qPCR. Three cases $(7 \%)$ were excluded from the data analysis, all due to RNA quality issue in the samples. Four cases failed to result part of the RAS mutation analysis (HRAS and/or NRAS), but as two had mutations in other genes (one in $B R A F$, the other a $P A X 8 / P P A R \gamma$ rearrangement), only the other two that had no mutations in other genes were excluded. The third case excluded failed both RET-PTC and $P A X 8 / P P A R \gamma$ analysis. In the final genotype-phenotype analysis, patients were included with either one positive mutation or who were genotyped for all cited molecular markers. A total of 39 such cases met the above criteria.

A comprehensive chart review was performed, including patients' demographics, family history, history of external beam or other radiation exposure, and disease characteristics such as histology and tumor size. The staging and the type of metastasis were based on initial surgery and the whole-body scan findings following the initial radioiodine ${ }^{131}$ I treatment.

Statistical analysis was performed with IBM SPSS Statistics for Windows v22 (IBM Corp., Armonk, NY). Chisquare and Fisher's exact tests were used when appropriate to compare the rates of the various mutations with different clinical characteristics (e.g., presence of lymph node metastasis or thyroiditis). The $p$-value was considered statistically significant when it was $<0.05$ and as a trend with borderline significance when it was $\geq 0.05$ and $<0.10$.

\section{Results}

\section{Patient characteristics}

A total of 39/42 patients were included in the final analysis. The number of thyroid cancer cases seen at RCHSD increased significantly after 2005 , with $89.7 \%$ of the cases diagnosed with non-medullary thyroid cancer after 2005, which is in accordance with the SEER incidence data for pediatric thyroid cancer (2). Demographic data are shown in Table 1 . The mean age at diagnosis was $14.7 \pm 2.6$ years, with females $($ mean $=14.9$ years) being slightly older than males $($ mean $=14.1$ years; $p=0.235)$. As in other pediatric series $(13,17,25,26)$, there was a female predominance $(74.4 \%)$. The majority of the patients were Hispanic $(56.4 \%)$ of Mexican American descent, and Caucasian (35.9\%; Table 1). The histologic cancer types included $28(71.8 \%)$ classic PTC, six $(15.4 \%)$ FVPTC, and five (12.8\%) FTC. The distribution is similar to the reported pediatric WDTC SEER data (25), for rates of PTC (64.5\%), FVPTC (24.7\%), and FTC (12.5\%).

Two of the patients with PTC had a history of radiation exposure. One was treated with cranial radiation for an 
Table 1. Patient Characteristics

\begin{tabular}{lc}
\hline Characteristic & No. $(\%)$ \\
\hline Age at diagnosis (years) & \\
Mean (SD), range & $14.7(2.6), 7.9-18.4$ \\
Sex & \\
Male/female & $10(25.6) / 29(74.4)$ \\
Ethnicity & \\
Caucasian & $14(35.9)$ \\
Hispanic & $22(56.4)$ \\
African American & $1(2.6)$ \\
South Asian & $2(5.1)$ \\
Histologic subtype & \\
PTC & $28(71.8)$ \\
FVPTC & $6(15.4)$ \\
FTC & $5(12.8)$ \\
Tumor size (cm) & \\
<2 & $15(38.5)$ \\
2-4 & $12(30.8)$ \\
$>4$ & $12(30.8)$ \\
Neck dissection & \\
Central & $7(17.9)$ \\
Central and lateral & $13(33.3)$ \\
Other & $1(2.6)$ \\
No neck dissection & $18(46.2)$ \\
Lymph node metastases & $21(53.8)$ \\
Pulmonary metastases & $3(8.1)$ \\
Thyroiditis & $16(41)$ \\
\hline
\end{tabular}

${ }^{\mathrm{a}}$ Lymph node metastasis at the completion of initial treatment. ${ }^{\mathrm{b}}$ Pulmonary metastases noted post initial radioiodine ${ }^{131} \mathrm{I}$ course. PTC, papillary thyroid carcinoma; FVPTC, follicular variant of PTC; FTC, follicular thyroid carcinoma.

anaplastic ependymoma and the other with cranial and spinal radiation for medulloblastoma. The latency period from radiation treatment to diagnosis of thyroid cancer was nine and seven years, respectively. Both patients' molecular testing was negative.

As detailed in Table 1, almost one third of the tumors were $2-4 \mathrm{~cm}$ in size, close to $30 \%$ were $>4 \mathrm{~cm}$, and the rest were $<2 \mathrm{~cm}$. Neck dissection was performed in 21/39 (53.8\%) patients; seven (33.3\%) had central neck dissection, 13 (61.9\%) both central and lateral, and one dissection of compartment I (not associated with an ectopic thyroid tissue). Neck dissections were planned if there were clinically and/or radiological positive nodal disease preoperatively, and occasionally neck dissections were performed based on the surgeon's determi- nation of pathologic nodal disease intraoperatively with judicious use of frozen sections. Prophylactic central compartment (level VI) or lateral neck dissections were not routinely performed at this institution. Twenty-one of the patients (53.8\%) were found to have pathologically positive nodal metastasis and almost all with PTC (95\%). Only one patient with FVPTC had lymph node metastasis at diagnosis, and none of those with FTC $(p=0.002)$. Radioiodine ablation was administered to $37 / 39$ patients. One subject did not receive radioactive iodine (RAI) treatment after thyroidectomy due to a small tumor $(<1 \mathrm{~cm})$ and one was lost to follow-up. All cases were presumed to be RAI avid at the time of their initial therapeutic ${ }^{131}$ I course, as this is more likely to be the case in pediatric tumors (27). The post ${ }^{131}$ I treatment whole-body scan revealed uptake indicative of neck lymph metastasis in four patients, all of whom already had positive lymph nodes identified during their initial thyroidectomy. Pulmonary metastases were noted, per available post ${ }^{131} \mathrm{I}$ data, in $2 / 26$ patients with PTC, and in one subject with FVPTC. The findings were confirmed by subsequent computed tomography (CT) in the two PTC cases. The mean initial ${ }^{131} \mathrm{I}$ dose was $130 \mathrm{mCi}$ (range 54-184.2 mCi). Four patients had more than one ${ }^{131} \mathrm{I}$ course due to persistent metastases. The mean follow-up period was 34.4 months.

Thyroiditis was diagnosed in 16/39 (41\%) patients based on either pathology or positive thyroid antibodies. Most had thyroglobulin ( $\mathrm{Tg}$ ) antibodies measured together with antithyroid peroxidase (anti-TPO) antibodies before their thyroidectomy, and all had documented post-thyroidectomy $\mathrm{Tg}$ level and antibody titers. Of the 39 patients, 28 had anti-TPO antibody testing, and $12(43 \%)$ were elevated. Thirteen $(81.25 \%)$ of those with thyroiditis were diagnosed with PTC, and three $(18.75 \%)$ with non-PTC $(p=0.27)$. From the cases with positive mutations, $62.5 \%$ of the PTC cases had thyroiditis compared with $20 \%$ of the non-PTC cases $(p=0.01)$. Patients with thyroiditis compared with those without thyroiditis had mutations in $68.7 \%$ versus $43.5 \%$, respectively $(p=0.12)$, and a $B R A F^{V 600 E}$ mutation was present in both groups. The small number of cases with mutations does not allow us to comment on whether thyroiditis affects the type of mutation noted.

\section{Mutational analysis}

Mutations were noted in 21/39 (53.8\%) samples. A detailed breakdown of the various mutations is shown in Table 2 .

Table 2. Distribution of Genetic Mutations/Alterations

\begin{tabular}{|c|c|c|c|c|c|c|c|c|c|}
\hline \multirow[b]{3}{*}{ Mutation } & \multirow[b]{3}{*}{ BRAF $^{\mathrm{V} 600 \mathrm{E}}$} & & & \multicolumn{5}{|c|}{ RAS } & \multirow[b]{3}{*}{ PAX8/PPAR $\gamma$} \\
\hline & & \multicolumn{2}{|c|}{ RET/PTC } & \multirow{2}{*}{$\begin{array}{c}\text { H codons } \\
12 / 13\end{array}$} & \multirow[b]{2}{*}{ H codon 61} & \multirow{2}{*}{$\begin{array}{c}K \text { codons } \\
12 / 13 / 61\end{array}$} & \multirow{2}{*}{$\begin{array}{c}N \text { codons } \\
12 / 13\end{array}$} & \multirow[b]{2}{*}{$N$ codon 61} & \\
\hline & & 1 & 3 & & & & & & \\
\hline Sample & 39 & 39 & 39 & 39 & 37 & 39 & 38 & 38 & 37 \\
\hline$n$ & 9 & 5 & 1 & 0 & 0 & 0 & 0 & 2 & 4 \\
\hline $\mathrm{M} / \mathrm{F}$ & $3 / 6$ & $1 / 4$ & $0 / 1$ & & & & & $0 / 2$ & $1 / 3$ \\
\hline PTC & 9 & 5 & 1 & & & & & 1 & \\
\hline FVPTC & 0 & 0 & 0 & & & & & 0 & 3 \\
\hline FTC & 0 & 0 & 0 & & & & & 1 & 1 \\
\hline$n$ total $(\%)$ & $9(23.1)$ & 6( & & & & $2(5.3)$ & & & $4(10.8)$ \\
\hline
\end{tabular}

$\mathrm{M}$, male; F, female. 


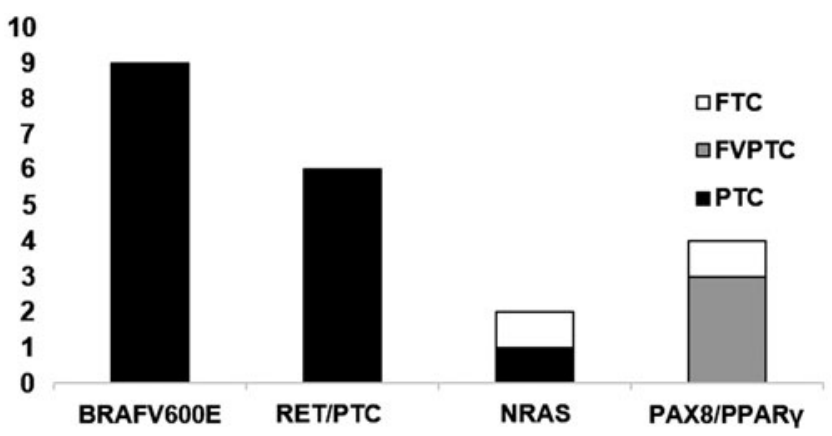

FIG. 1. Mutational analysis by histology.

Multiple mutations were not identified in any patient. The most prevalent mutation was $B R A F^{V 600 E}$, found exclusively in PTC (Fig. 1). No BRAF ${ }^{K 601 E}$ was noted. A total of six RET/ $P T C$ rearrangements were identified, and only in PTC. Three out of six FVPTC were positive for PAX8/PPAR $\gamma$, which was also found in one FTC. Two NRAS codon 61 mutations (c.181C>A, p.Q61K) were also found, one in FTC and one in PTC.

Of the 28 patients with classic PTC, $57.1 \%(n=16)$ had mutations. Mutations were noted in $50 \%(n=3 / 6)$ of those with FVPTC and in $40 \%(n=2 / 5)$ of those with FTC, but the numbers in those two cancer types were small. BRAF V600E was the most common mutation in PTC (Fig. 2). It was found in $32.1 \%$ of PTC cases, and $77.8 \%$ and $22.2 \%$ of those cases were Hispanic and Caucasian, respectively $(p=0.10)$. RET/ PTC was found in $21.4 \%$ of PTC cases and was evenly distributed, with $33.3 \%$ being Hispanic and $33.3 \%$ Caucasian. The five patients with a RET/PTC1 rearrangement tended to have smaller tumors, four being $<2 \mathrm{~cm}$, and only one $>4 \mathrm{~cm}$, but $80 \%$ of them had positive lymph nodes.

Approximately $89 \%$ of the $B R A F^{V 600 E}$ mutations were found in adolescents $>15$ years of age, and $11.1 \%$ in $\leq 15$ years old (Fig. 3), while RET/PTC rearrangements were exclusively found in children $<15$ years old ( $p=0.003$ ). Taking into consideration the female predominance in WDTC, no sex differences were noted in the relative rate of $B R A F^{V 600 E}$ mutations and RET/PTC rearrangements $(p=0.6)$.

There was no statistically significant difference noted in the tumor size, lymph node status, and iodine-avid distant metastasis at the completion of the initial treatment (thyroidectomy and ${ }^{131}$ I ablation), based on the presence or the type of mutations. Of all the patients found to be positive for a

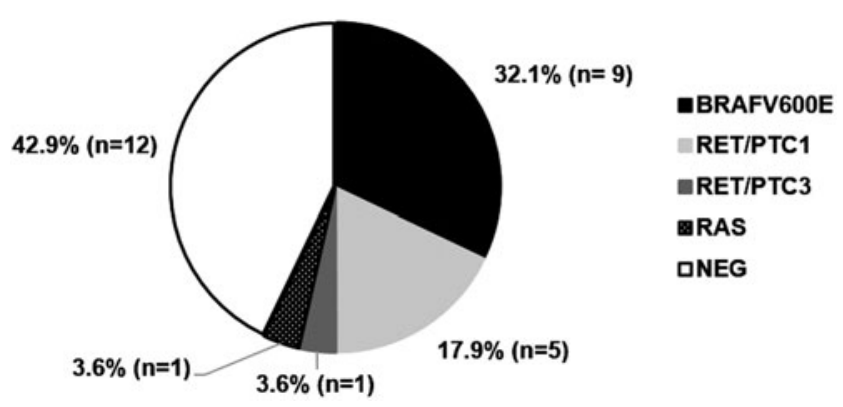

FIG. 2. Mutational analysis in PTC.

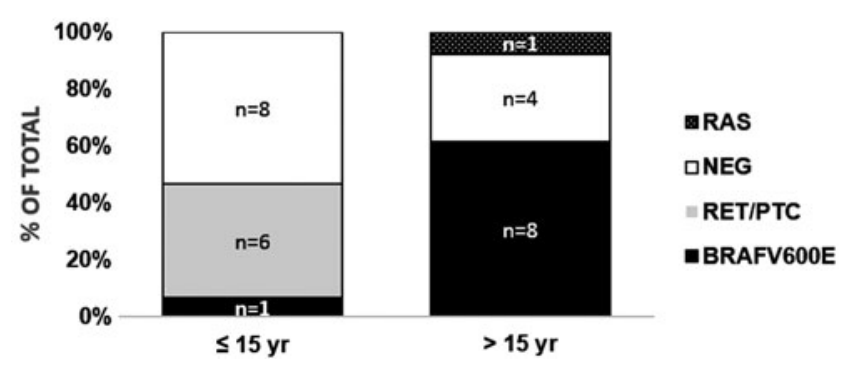

FIG. 3. Mutational distribution by age in PTC.

mutation, $66.7 \%$ underwent a neck dissection in comparison with $38.9 \%$ of those who did not have a mutation $(p=0.113)$. Alternatively, those who presented with positive lymph nodes at diagnosis were not more likely to have positive mutations detected. Of the PTC cases positive for a mutation, $81.25 \%$ presented with lymph node metastasis at diagnosis versus $58.3 \%$ of those without a mutation $(p=0.231)$. Close to $89 \%(88.9 \%)$ of the cases with a $B R A F^{V 600 E}$ mutation and $83.3 \%$ of the cases with a RET/PTC rearrangement had central and/or lateral neck dissection, all with positive lymph nodes. Of the $B R A F^{V 600 E}$-positive PTC tumors, $22.2 \%$ were $>4 \mathrm{~cm}$, and of the cases with a RET/PTC rearrangement, $33 \%$ were $>4 \mathrm{~cm}(p=0.393)$. There were no iodine-avid distant metastases noted in the PTC cases positive for a mutation, whereas two cases, representing $18.2 \%$ of the PTC cases without a mutation, had distant pulmonary metastasis identified at diagnosis. The FVPTC case with pulmonary metastasis was positive for a $P A X 8 / P P A R \gamma$ rearrangement.

\section{Discussion}

The presence of the common mutations and rearrangements reported for adults with WDTC has been described previously in non-medullary pediatric thyroid carcinoma (12-19). However, prior pediatric studies tended to be small, and typically examined only one type of mutation, with recent studies focusing on $B R A F^{V 600 E}(15,16)$. The current study is the first pediatric study to examine all four mutation types simultaneously on thyroidectomy-obtained thyroid tissue from histologically confirmed WDTC using a commercially available analysis, performed by Quest Diagnostics (23). The recently published pediatric guidelines (28) state that molecular studies on fine-needle aspiration (FNA) cannot be recommended in routine clinical practice, as they are not yet validated. Data from this study may help fill some of the knowledge gaps. The currently reported study population is mostly of Hispanic (Mexican American) and Caucasian descent (both groups representing $92.3 \%$ of all cases). Due to the lack of long-term follow-up and very small number of recurrences (data not shown), only genotype-phenotype correlations are reported on, with the clinical presentation and course up to six months post-diagnosis. Buryk et al. recently published their experience with mutational analysis of these four genes on FNA material from thyroid nodules from 89 pediatric patients up to the age of 18 years, of whom 24 had thyroid cancer, and only 12 had PTC (29). However, all nodules with mutations were found to be malignant, similar to their earlier conclusions in a pediatric study on patients up to 21 years of age, with molecular data available on 66 FNAs (30). 
It was noted that $56.4 \%$ of the present pediatric cohort was Hispanic, and $35.9 \%$ was Caucasian. This is similar to their relative distribution in the general pediatric population in San Diego County ( $<18$ years old), which is $45.4 \%$ versus $34.1 \%$, respectively (31). This is in contrast to SEER data, where the incidence of WDTC was greater in white compared with Hispanic children (2) and may be due to the more varied origins of Hispanic patients nationally, whereas in this San Diego cohort they were all Mexican American. BRAF $F^{V 600 E}$ was the most common mutation in all cases and was exclusively found in PTC cases. It was noted mainly in older adolescents of Hispanic descent, a finding that was not recognized previously, and will require corroboration in future studies that also involve Hispanic subjects. RET/PTC rearrangements in PTC were exclusively found in younger patients ( $\leq 15$ years old), with a lower prevalence than prior U.S. pediatric studies. It is unclear if puberty has an impact on the type of mutation or whether it is just the age itself. The present finding of a cutoff at 15 years of age affecting the likelihood of being positive for a mutation (Fig. 3), while arbitrary, should be further explored. At the completion of the initial treatment, there was no statistically significant difference between tumor size and lymph node metastases based on the presence or type of the mutation; the number of distant metastasis is too small to draw any conclusions. Distant metastases were primarily identified with post-therapeutic ${ }^{131}$ I whole-body scans. Other imaging such as CT was not done in all of the patients. The majority of children with pulmonary metastases have micronodular disease that typically demonstrates excellent RAI uptake. Because of this, distant metastases in children are more amenable and responsive to ${ }^{131} \mathrm{I}$ therapy compared with adults. In the present cohort, Tg levels were measured in each patient post treatment, and there was no suspicion for metastases based on those levels.

$B R A F^{V 600 E}$ is considered to be the most common mutation in adult thyroid carcinoma $(4-6,32)$ and was initially thought to have a much lower prevalence in the pediatric population. In a series of 15 cases of children exposed to radiation (Chernobyl), no BRAF $F^{V 600 E}$ mutations were found in those $<15$ years of age, whereas 8/33 (24\%) cases in the older age group (15-31 years old) harbored this mutation (12); this latter rate does not truly reflect pediatric patients only. In two pediatric series of sporadic PTC published a decade ago, the $B R A F^{V 600 E}$ mutation prevalence was $0 \%$ (13) and $20 \%$ (14), respectively. In two more recent reports from the United States, the rates were higher $(15,16)$, perhaps signifying a shift. In the first study, the $B R A F^{V 600 E}$ mutation was detected in $63 \%$ of pediatric PTC and FVPTC cases $(n=27)$ and $71.4 \%$ of classic PTC cases $(n=21)(15)$. The mean age of the cohort was 18.6 years (range $5.8-21.2$ years). The authors did not find any significant correlation between $B R A F^{V 600 E}$ status and age, though most of their $B R A F^{V 600 E}$-positive cases $(70.6 \%)$ were found in children $>15$ years of age, similar to the finding reported here. Previous reports speculated that higher rates of $B R A F$ mutations likely reflect an older age distribution (33). Another recent study found $B R A F^{V 600 E}$ mutations in $36.8 \%(n=19)$ of their overall cohort and in $63.6 \%(n=11)$ of PTC cases (16). The reported median age was 13.6 years (range $2.8-18$ years). Of the $B R A F^{V 600 E}$ positive cases, 4/7 were found in children $>15$ years of age. This study had a larger cohort of 39 cases, with 28 of those being classic PTC. A higher prevalence of $B R A F^{V 600 E} \mathrm{mu}-$ tation was also found compared with the older pediatric reports $(13,14)$. The present study reports $23 \%$ of all cases and $32.1 \%$ of the PTC cases being positive for $B R A F^{V 600 E}$. The method used for the detection of the $B R A F^{V 600 E}$ mutation was allele-specific real-time PCR, which is considered to be more sensitive than Sanger sequencing. In order to verify the results, the mutations were confirmed by Sanger sequencing in $6 / 10$ of the $B R A F^{V 600 E}$-positive samples. Four of the samples failed to amplify due to technical reasons. In agreement with two recent reports $(15,16)$, the majority of the $B R A F^{V 600 E_{-}}$ positive cases were found in children $>15$ years of age. The finding is important, as it has been speculated in the past that the presence of a $B R A F^{V 600 E}$ mutation might contribute to the different biological behavior of adult versus pediatric PTC. The relationship between this mutation and the clinicopathological outcomes of PTC in adults have been investigated in several studies (4,34-37). There is no consensus regarding the correlation of the disease characteristics and the presence of a $B R A F$ mutation. In the majority of the studies, significant associations have been found between the presence of a $B R A F$ mutation and extrathyroidal invasion, advanced stages, distant metastasis, thyroid recurrence, and loss of RAI avidity in the recurrent thyroid cancer. However, a recent large study of adults with PTC failed to demonstrate the same correlations (37). This might be explained by recent findings from the Cancer Genome Atlas Research Network, which suggest that $B R A F^{V 600 E}$-positive PTC should not be considered a homogeneous group in clinical studies (38).

Fewer studies have addressed the same issue in pediatric thyroid carcinoma, but in none of those was presence of the $B R A F^{V 600 E}$ mutation associated with more aggressive disease $(13,39)$, or correlated with the extent of the disease at diagnosis or risk factors associated with poor prognosis $(15,16)$. The present study confirms that latter observation, but like the other small pediatric studies, it is not powered to detect a significant association between the presence of $B R A F^{V 600 E}$ and tumor behavior.

Although the prevalence of RET/PTC rearrangements in thyroid tumor varies in different series, it has been reported to be more frequent in childhood than in adulthood thyroid cancer $(18,40)$. Of the 13 different types of $R E T / P T C$ rearrangements described, RET/PTC1 and RET/PTC3 are the most common. RET/PTC1 and in particular RET/PTC3 have been highly associated with radiation-induced PTC (18). None of the RET/PTC cases in the current report had a history of radiation-induced PTC. RET/PTC rearrangements in this cohort were found in $21.4 \%$ of the PTC cases, which represents a much lower prevalence than that found in prior pediatric studies, such as a report of an overall frequency of $45.5 \%$ in a cohort of 33 American children with sporadic PTC (17). In a recent small pediatric series on FNA material, 3/12 PTC cases had RET/PTC rearrangements (25\%) (29). In a report from Italy, $40 \%$ of children with PTC, unexposed to radiation, were positive for $R E T / P T C$ rearrangements (19). All of the current RET/PTC positive cases were children $\leq 15$ years of age. When Elisei et al. compared the frequency of $R E T / P T C$ rearrangements in children and adults within the same country, they did not find any significant difference, and they concluded that age does not predict the presence of RET/ PTC rearrangements in PTC, but rather that it is a matter of different ethnic groups (40). The cohort presented here 
consists predominantly of children of Hispanic descent or Caucasians (Table 1). Both RET/PTC and $B R A F^{V 600 E}$ were found only in classic PTC $(n=28)$. A novel finding from this cohort was the high rate of $B R A F^{V 600 E}$ mutations in those of Hispanic descent ( $77.8 \%$ of cases). This contrast with RET/ $P T C$ rearrangements, which were evenly distributed.

The PAX8/PPAR $\gamma$ rearrangement is found in $30-40 \%$ of adult FTC, and rarely in FVPTC (11), whereas 3/6 FVPTC cases in the present study were positive for $P A X 8 / P P A R \gamma$, and $1 / 5$ cases with FTC was positive for a $P A X 8 / P P A R \gamma$ rearrangement. A larger series is needed to explore whether these findings are consistent in pediatric WDTC.

In the current study, a NRAS Q61 mutation was found in two $(5.1 \%)$ cases (one FTC, one PTC). The low mutation frequency for $R A S$ mutations in pediatric PTC $(3.6 \%)$ is similar to those reported previously (22-24), and the significance of the mutation frequency for $R A S$ mutations in pediatric FTC (20\%) needs to be further investigated due to the small sample size in this category of patients.

Thyroiditis was documented in $41 \%$ cases, a higher rate than in the general population, where $4.8 \%$ of adolescents (12-19 years old) in the United States are reported to have positive anti-TPO antibodies (41). In addition, the finding of thyroiditis being more prevalent in PTC $(81.5 \%)$ versus nonPTC $(18.7 \%)$ cases $(p=0.27)$ may reach significance in a larger cohort. There are mixed data reported on the association of autoimmune thyroiditis and differentiated thyroid cancer. Most studies based on FNA biopsy report no correlation, whereas the studies on thyroidectomy tissue report a positive relationship. In patients with Hashimoto's thyroiditis, the average rate of PTC is $1.20 \%$ in studies using FNA and $27.56 \%$ using tissue from thyroidectomies (42). A recent study based on analysis of thyroidectomy tissue failed to demonstrate an association between anti-TPO antibodies and the diagnosis of thyroid cancer (43). In a study from Italy, 39/ 365 children with autoimmune thyroiditis had FNA performed for suspicious thyroid nodules, and 11 were found to have a PTC on histology, giving an overall prevalence of $3 \%$ (44).

One of the limitations of the study is that it is retrospective. Obtaining consecutive cases helps eliminate some bias. The single-center sample size is small, although larger than previous studies in pediatrics. The mean follow-up period was 2.9 years. Since WDTC is typically a slowly progressive tumor, a longer follow-up is needed for better genotypephenotype analysis of recurrence. Extracted DNA and RNA from FFPE tissues are known to be fragmented and prone to degradation over time (45). The samples that failed to result were from patients diagnosed between 2001 and 2008 and not necessarily from the oldest samples. Overall, genotyping of $R E T / P T C$ and $R A S$ was associated with some technical difficulties in a minority of patients, which did not seem to affect the overall conclusions.

In conclusion, this study demonstrates that in a pediatric population of WDTC consisting mostly of Hispanic and Caucasian patients, the frequency of the $B R A F^{V 600 E}$ mutation is comparable to that found in the adult population, and it is mostly observed in those $>15$ years old and of Hispanic descent. RET/PTC rearrangements were less prevalent in this cohort compared with prior pediatric studies. More advanced molecular analysis using next-generation sequencing will likely reveal other types of mutations, rearrangements, and fusions that may affect the genotype-phenotype correlations. A larger, multicenter, and ethnically diverse pediatric cohort followed long term is needed to study genotype-phenotype correlations better in thyroid cancer at diagnosis and beyond.

\section{Acknowledgments}

This study was presented as an abstract at the 2014 Endocrine Society meeting and the 2014 American Thyroid Association meeting.

\section{Author Disclosure Statement}

F.M.H., F.W., M.M., R.E.R., and S.C. are employees of Quest Diagnostics, and some have equity interest in the company. No other conflicts of interest exist. No competing financial interests exist for the remaining authors.

\section{References}

1. Dinauer CA, Breuer C, Rivkees SA 2008 Differentiated thyroid cancer in children: diagnosis and management. Curr Opin Oncol 20:59-65.

2. Surveillance, Epidemiology, and End Results (SEER) Program. SEER*Stat Database Incidence-SEER 13 Regs Research Data, Nov 2013 Sub (1973-2011) <Katrina/Rita Population Adjustment>-Linked To County AttributesTotal U.S., 1969-2012 Counties, National Cancer Institute, DCCPS, Surveillance Research Program, Surveillance Systems Branch, released April 2014, based on the November 2013 submission.

3. Hay ID, Gonzalez-Losada T, Reinalda MS, Honetschlager JA, Richards ML, Thompson GB 2010 Long-term outcome in 215 children and adolescents with papillary thyroid cancer treated during 1940 through 2008. World J Surg 34:11921202.

4. Xing M $2005 B R A F$ mutation in thyroid cancer. Endocr Relat Cancer 12:245-262.

5. Kimura ET, Nikiforova MN, Zhu Z, Knauf JA, Nikiforov YE, Fagin JA 2003 High prevalence of BRAF mutations in thyroid cancer: genetic evidence for constitutive activation of the $R E T / P T C-R A S-B R A F$ signaling pathway in papillary thyroid carcinoma. Cancer Res 63:1454-1457.

6. Cohen Y, Xing M, Mambo E, Guo Z, Wu G, Trink B, Beller U, Westra WH, Ladenson PW, Sidransky D 2003 BRAF mutation in papillary thyroid carcinoma. J Natl Cancer Inst 95:625-627.

7. Nikiforov YE 2002 RET/PTC rearrangement in thyroid tumors. Endocr Pathol 13:3-16.

8. Namba H, Rubin SA, Fagin JA 1990 Point mutations of ras oncogenes are an early event in thyroid tumorigenesis. Mol Endocrinol 4:1474-1479.

9. Esapa CT, Johnson SJ, Kendall-Taylor P, Lennard TW, Harris PE 1999 Prevalence of $R A S$ mutations in thyroid neoplasia. Clin Endocrinol 50:529-535.

10. Nikiforov YE, Nikiforova MN 2011 Molecular genetics and diagnosis of thyroid cancer. Nat Rev Endocrinol 7:569-580.

11. Nikiforova MN, Lynch RA, Biddinger PW, Alexander EK, Dorn GW, Tallini G, Kroll TG, Nikiforov YE 2003 RAS point mutations and $P A X 8-P P A R \gamma$ rearrangement in thyroid tumors: evidence for distinct molecular pathways in thyroid follicular carcinoma. J Clin Endocrinol Metab 88:23182326.

12. Kumagai A, Namba H, Saenko VA, Ashizawa K, Ohtsuru A, Ito M, Ishikawa N, Sugino K, Ito K, Jeremiah S 2004 
Low frequency of BRAF T1796A mutations in childhood thyroid carcinomas. J Clin Endocrinol Metab 89:42804284.

13. Penko K, Livezey J, Fenton C, Patel A, Nicholson D, Flora M, Oakley K, Tuttle RM, Francis G 2005 BRAF mutations are uncommon in papillary thyroid cancer of young patients. Thyroid 15:320-325.

14. Rosenbaum E, Hosler G, Zahurak M, Cohen Y, Sidransky $\mathrm{D}$, Westra WH 2005 Mutational activation of $B R A F$ is not a major event in sporadic childhood papillary thyroid carcinoma. Mod Pathol 18:898-902.

15. Henke LE, Perkins SM, Pfeifer JD, Ma C, Chen Y, DeWees T, Grigsby PW 2014 BRAF V600E mutational status in pediatric thyroid cancer. Pediatr Blood Cancer 61:11681172.

16. Givens DJ, Buchmann LO, Agarwal AM, Grimmer JF, Hunt JP 2014 BRAF V600E does not predict aggressive features of pediatric papillary thyroid carcinoma. Laryngoscope 124: E389-E393.

17. Fenton CL, Lukes Y, Nicholson D, Dinauer CA, Francis GL, Tuttle RM 2000 The RET/PTC Mutations are common in sporadic papillary thyroid carcinoma of children and young adults. J Clin Endocrinol Metab 85:1170-1175.

18. Nikiforov YE, Rowland JM, Bove KE, Monforte-Munoz H, Fagin JA 1997 Distinct pattern of ret oncogene rearrangements in morphological variants of radiation-induced and sporadic thyroid papillary carcinomas in children. Cancer Res 57:1690-1694.

19. Bongarzone I, Fugazzola L, Vigneri P, Mariani L, Mondellini P, Pacini F, Basolo F, Pinchera A, Pilotti S, Pierotti M 1996 Age-related activation of the tyrosine kinase receptor protooncogenes RET and NTRK1 in papillary thyroid carcinoma. J Clin Endocrinol Metab 81:2006-2009.

20. Fenton C, Anderson J, Lukes Y, Dinauer CW, Tuttle R, Francis G 1999 RAS mutations are uncommon in sporadic thyroid cancer in children and young adults. J Endocrinol Investig 22:781-789.

21. Nikiforov YE, Nikiforova MN, Gnepp DR, Fagin JA 1996 Prevalence of mutations of $R A S$ and p53 in benign and malignant thyroid tumors from children exposed to radiation after the Chernobyl nuclear accident. Oncogene 13: 687-693.

22. Suchy B, Waldmann V, Klugbauer S, Rabes H 1998 Absence of $R A S$ and p53 mutations in thyroid carcinomas of children after Chernobyl in contrast to adult thyroid tumours. Br J Cancer 77:952.

23. Nikita M, Jiang W, Newburry R, Phillips S, Reitz R, Waldman F, Hantash F, Newfield R 2014 Genetic variability in 43 pediatric thyroid cancer cases and correlation with their clinical presentation up to 6 months postdiagnosis. Thyroid 24:A25-26.

24. Cheng S-M, Qu K, Abdool A, Sferruzza A, Waldman F, Reitz RE 2012 A molecular diagnostic panel for thyroid cancer disease management. J Clin Oncol 30:(suppl; abstr 5510).

25. Hogan AR, Zhuge Y, Perez EA, Koniaris LG, Lew JI, Sola JE 2009 Pediatric thyroid carcinoma: incidence and outcomes in 1753 patients. J Surg Res 156:167-172.

26. Scholz S, Smith JR, Chaignaud B, Shamberger RC, Huang SA 2011 Thyroid surgery at Children's Hospital Boston: a 35-year single-institution experience. J Pediatr Surg 46: 437-442.

27. Jarzạb B, Handkiewicz-Junak D, Włoch J 2005 Juvenile differentiated thyroid carcinoma and the role of radioiodine in its treatment: a qualitative review. Endocr Relat Cancer 12:773-803.

28. Francis G, Waguespack SG, Bauer AJ, Angelos P, Benvenga S, Cerutti J, Dinauer CA, Hamilton JK, Hay ID, Luster M; The American Thyroid Association Guidelines Task Force on Pediatric Thyroid Cancer 2015 Management guidelines for children with thyroid nodules and differentiated thyroid cancer. Thyroid 25:716-759.

29. Buryk MA, Simons JP, Picarsic JL, Monaco SE, Ozolek JA, Joyce J, Gurtunca N, Nikiforov YE, Witchel SF 2015 Can malignant thyroid nodules be distinguished from benign thyroid nodules in children and adolescents by clinical characteristics? A review of 89 pediatric patients with thyroid nodules. Thyroid 25:392-400.

30. Monaco SE, Pantanowitz L, Khalbuss WE, Benkovich VA, Ozolek J, Nikiforova MN, Simons JP, Nikiforov YE 2012 Cytomorphological and molecular genetic findings in pediatric thyroid fine-needle aspiration. Cancer Cytopathol 120:342-350.

31. Bureau USC Children Characteristics, San Diego, California 2008-2012. Available at: http://factfinder.census. gov/faces/tableservices/jsf/pages/productview.xhtml?pid= ACS_12_5YR_S0901\&prodType $=$ table

32. Jung CK, Little MP, Lubin JH, Brenner AV, Wells SA, Sigurdson AJ, Nikiforov YE 2013 The increase in thyroid cancer incidence during the last four decades is accompanied by a high frequency of $B R A F$ mutations and a sharp increase in $R A S$ mutations. J Clin Endocrinol Metab 99:E276-E285.

33. Yamashita S, Saenko V 2007 Mechanisms of disease: molecular genetics of childhood thyroid cancers. Nat Clin Pract Endocrinol Metab 3:422-429.

34. Namba H, Nakashima M, Hayashi T, Hayashida N, Maeda S, Rogounovitch TI, Ohtsuru A, Saenko VA, Kanematsu T, Yamashita S 2003 Clinical implication of hot spot BRAF mutation, V599E, in papillary thyroid cancers. J Clin Endocrinol Metab 88:4393-4397.

35. Nikiforova MN, Kimura ET, Gandhi M, Biddinger PW, Knauf JA, Basolo F, Zhu Z, Giannini R, Salvatore G, Fusco A $2003 B R A F$ mutations in thyroid tumors are restricted to papillary carcinomas and anaplastic or poorly differentiated carcinomas arising from papillary carcinomas. J Clin Endocrinol Metab 88:5399-5404.

36. Kim KH, Kang DW, Kim SH, Seong IO, Kang DY 2004 Mutations of the $B R A F$ gene in papillary thyroid carcinoma in a Korean population. Yonsei Med J 45:818-821.

37. Gouveia C, Can NT, Bostrom A, Grenert JP, van Zante A, Orloff LA 2013 Lack of association of BRAF mutation with negative prognostic indicators in papillary thyroid carcinoma: the University of California, San Francisco, experience. JAMA Otolaryngol Head Neck Surg 139:1164-1170.

38. Network CGAR 2014 Integrated genomic characterization of papillary thyroid carcinoma. Cell 159:676-690.

39. Sassolas G, Hafdi-Nejjari Z, Ferraro A, Decaussin-Petrucci M, Rousset B, Borson-Chazot F, Borbone E, Berger N, Fusco A 2012 Oncogenic alterations in papillary thyroid cancers of young patients. Thyroid 22:17-26.

40. Elisei R, Romei C, Vorontsova T, Cosci B, Veremeychik V, Kuchinskaya E, Basolo F, Demidchik EP, Miccoli P, Pinchera A 2001 RET/PTC rearrangements in thyroid nodules studies in irradiated and not irradiated, malignant and benign thyroid lesions in children and adults. J Clin Endocrinol Metab 86:3211-3216.

41. Hollowell JG, Staehling NW, Flanders WD, Hannon WH, Gunter EW, Spencer CA, Braverman LE 2002 Serum TSH, 
T4, and thyroid antibodies in the United States population (1988 to 1994): National Health and Nutrition Examination Survey (NHANES III). J Clin Endocrinol Metab 87:489-499.

42. Jankovic B, Le KT, Hershman JM 2013 Hashimoto's thyroiditis and papillary thyroid carcinoma: is there a correlation? J Clin Endocrinol Metab 98:474-482.

43. Azizi G, Keller J, Lewis M, Piper K, Puett D, Rivenbark KM, Malchoff C 2014 Association of Hashimoto's thyroiditis with thyroid cancer. Endocr Relat Cancer 21:845-852.

44. Corrias A, Cassio A, Weber G, Mussa A, Wasniewska M, Rapa A, Gastaldi R, Einaudi S, Baronio F, Vigone MC 2008 Thyroid nodules and cancer in children and adolescents affected by autoimmune thyroiditis. Arch Pediatr Adolesc Med 162:526-531.
45. Srinivasan M, Sedmak D, Jewell S 2002 Effect of fixatives and tissue processing on the content and integrity of nucleic acids. Am J Pathol 161:1961-1971.

Address correspondence to:

Ron S. Newfield, MD

Department of Pediatrics

University of California, San Diego

and Rady Children's Hospital San Diego

3020 Children's Way MC 5103

San Diego, CA 92123

E-mail: rnewfield@ucsd.edu 